\title{
LA HIBRIDEZ NARRATIVA EN JUAN RULFO Y RICARDO GARIBAY: 1945-1955
}

\author{
Anadeli Bencomo \\ University of Houston \\ abencomo@central.uh.edu
}

\author{
Andrés Vázquez \\ University of Houston \\ vazandres16@gmail.com
}

Resumen: Este artículo analiza la hibridez narrativa en la obra cuentística de Juan Rulfo y Ricardo Garibay para señalar en qué medida estos autores representan el rasgo heterogéneo de las escrituras de la modernidad en América Latina. En los relatos de Rulfo y Garibay veremos cómo dos universos distintos (el rural y urbano, el oral y el letrado) se combinan a partir de estrategias transculturadoras. A una temática regional se le vierte dentro de modos narrativos innovadores como la prosa coloquial o la prosa oral, el monólogo interior, el relato fragmentado.

Palabras clave: narrativas transculturadas, prosa oral, cuentos rurales en México postrevolucionario, narrativa moderna.

\begin{abstract}
This article analyzes the narrative hybridity in the short stories written by Juan Rulfo and Ricardo Garibay to show to what extent these authors represent the heterogeneous mark of modern literature in Latin America. In Rulfo's and Garibay's stories, two divergent worlds coexist (the rural and the urban, the oral and the literary) through mechanisms related to narrative transculturation. Local themes are expressed through innovative formal techniques, such as that of colloquial or oral prose, flow of consciousness or a fragmented narrative.
\end{abstract}

Keywords: narrative transculturation, oral prose, rural short-stories in post-revolutionary Mexico, modern narrative.

\section{DOI: https://doi.org/10.24029/lejana.2017.10.157}

Recibido: el 7 de julio de 2017

Aceptado: el 13 de octubre de 2017

Publicado: el 4 de noviembre de 2017 
Cuando nos aproximamos a los cuentos de Juan Rulfo y Ricardo Garibay, escritos entre los años 1945 y 1955, destaca el mundo rural dentro del cual se desenvuelven la gran parte de estos relatos. La temática y la ambientación nos remiten a ciertos tópicos usuales dentro de las narrativas regionalistas y criollistas que les precedieron. Esta afinidad es propiciada, además, por el empleo de la prosa realista como recurso asociado a una tradición narrativa que inclúa en la primera mitad del siglo XX tanto a la vertiente criollista (Horacio Quiroga, por ejemplo), como las variantes indigenistas (José María Arguedas) o las del realismo urbano (Julio Ramón Ribeyro). Estos modelos narrativos se prestaban idóneamente para describir una realidad social cambiante, que en el caso mexicano tenía que vérselas con una Revolución que modificaría profunda e irremediablemente el entorno rural, sus personajes, su economía, su paisaje.

Las narrativas del criollismo regionalista que pudieron perder vigencia en otros contextos latinoamericanos se hacían todavía pertinentes en un México postrevolucionario, que apostaba al proyecto de Unidad Nacional como vía de construcción de un imaginario que incluyera a los distintos sectores de la población (campo, ciudad, asentamientos indígenas). A este imaginario lo modelaban, entre otros discursos, el literario, el cinematográfico, el radial, el fotográfico, y los relatos de Rulfo y Garibay se inscribían dentro de esta voluntad referencial.

Al mismo tiempo, desde la segunda década del siglo Xx habían ganado terreno las vanguardias literarias que proponían nuevos modos narrativos. En el caso mexicano, las corrientes vanguardistas de corte predominantemente urbano, como el estridentismo, convivirían con la novela de la Revolución, que se ocupaba de narrar las luchas que sacudían a la provincia mexicana. Se daba así una situación de una literatura bicéfala, puesto que de un lado estaban las modas vanguardistas asociadas a los centros urbanos y, por otro, estaban estas narrativas realistas de la Revolución que se ambientaban y se relacionaban predominantemente con la vida rural.

Dentro del marco de la narrativa postrevolucionaria en México, Juan Rulfo y Ricardo Garibay se reconocen como dos autores que dedicaron buena parte de su obra a retratar de manera realista la vida en ciertas zonas rurales de México. Además, es notoria su exploración de nuevos modos de escritura, como la búsqueda de una prosa que incorporara los giros y el ritmo del habla rural dentro de la escritura literaria, abriendo paso a procesos de hibridez que abordaremos en las siguientes páginas. En necesario aclarar que Garibay se ocuparía del tema y el ambiente rural en las primeras etapas de su obra, puesto que más tarde se consagraría dentro del campo de la crónica (Las glorias del Gran Púas, 1978) o de la novela que ya no se circunscribía al universo campesino (Bellísima bahía, 1968).

En esta oportunidad analizaremos los cuentos de Ricardo Garibay y Juan Rulfo a partir del concepto de transculturación narrativa (Ángel Rama). Nuestra propuesta de lectura consiste en revisar de qué manera estos autores están innovando dentro del modelo del cuento rural realista. Más específicamente, nos detendremos en dos de los tres niveles señalados por Rama en su discusión sobre la transculturación narrativa: el discurso y la estructura de los relatos. De igual manera, prestaremos atención a las dinámicas de producción y recepción de estos textos que obedecen, a nuestro juicio, a los parámetros de la heterogeneidad cultural a la manera definida por Cornejo Polar. El cuento se presta particularmente bien para identificar las estructuras y procedimientos discursivos asociados a la representación de culturas híbridas, como la mexicana; 
en muy pocas páginas, un relato rulfiano o garibayesco nos pone en contacto directo con tales procedimientos, permitiéndonos la elaboración de conclusiones que se ajusten detalladamente al corpus descrito.

\section{Prosa oral y prosa coloquial}

En la lectura de los cuentos producidos por nuestros autores en la década de 1945-1955, llama la atención un particular trabajo con la prosa que tiene que ver con la incorporación textual de inflexiones propias del habla, de la lengua oral. Cuando nos referimos a inflexiones, queremos significar aquellos rasgos más directamente ligados al habla y, dentro de nuestro corpus, más específicamente vinculados con el lenguaje propio de la cultura rural mexicana.

Con respecto a los paradigmas asociados a las culturas orales, contamos con el reconocido estudio de Walter Ong (Orality and Literacy, 1982) que distingue las características de narraciones orales, como las de los poemas homéricos o historias bíblicas. En este libro, Ong propone la idea de que la escritura, más que cualquier otra innovación tecnológica, ha transformado la conciencia y el pensamiento humano. Según Ong, la escritura es una tecnología que una vez interiorizada, reestructura la conciencia humana. La escritura, al distanciarnos de nuestra realidad inmediata, nos permitiría desarrollar pensamientos abstractos y observaciones introspectivas.

Ong expone algunas características que distinguen al pensamiento oral del pensamiento tipográfico o electrónico. El primer grupo de ellas nace de las restricciones inherentes al hecho de que, en la oralidad, las palabras solo existen dentro del ámbito oral-auditivo y no dentro del visual. Los recursos asociados a estas características facilitan a la mente el recordar y organizar los pensamientos: la preferencia hacia la parataxis o la conjunción de dos elementos gramaticales del mismo nivel, en lugar de la hipotaxis o la subordinación, que además de ser gramaticalmente más sofisticada, sigue un pensamiento jerárquico; el uso de fórmulas expresivas como el epíteto (por ejemplo, "el valiente héroe"); y las repeticiones. Por su naturaleza reiterativa y formularia, Ong describe el pensamiento oral como conservador y tradicionalista; es decir, hostil a innovaciones o experimentaciones.

Ong también destaca la tendencia de las culturas orales a conceptualizar y articular su saber a través de referencias a su mundo inmediato, their human lifeworld. Por lo tanto, explica Ong, el pensamiento de las culturas orales se caracteriza por un conocimiento que se adquiere a través de la participación y la empatía, más que a través de un distanciamiento objetivo; enfocándose en el presente y recurriendo al pasado únicamente cuando este es relevante al presente (homeostático). Además, este conocimiento es situacional más que abstracto y tiene matices agonales, de combate o lucha. A pesar de que estas características contribuyen a entender el pensamiento oral y, por ende, los cambios brindados por la escritura, el crítico estadounidense aclara que estas características no son exhaustivas.

En los cuentos de Rulfo y Garibay nos interesa, a su vez, destacar sus propios mecanismos de representación de la oralidad dentro de la escritura, pues difieren del molde prescrito por Ong al prestarse a articulaciones transculturadoras donde se mezclan de manera 
particular los recursos del discurso oral y el escrito. En otras palabras, analizaremos en qué medida la oralidad y las voces regionales se incorporan dentro de la prosa, poniendo en práctica hibridaciones entre la escritura literaria y la lengua hablada propia del contexto representado en las historias.

En primer lugar, atenderemos a la distinción entre dos expresiones de la hibridación escritura-habla: la prosa coloquial y la prosa oral. Por prosa coloquial entendemos la transposición léxica y prosódica del habla de los personajes rurales directamente dentro del texto, sin mediaciones de un narrador letrado. Este tipo de prosa la identificamos en cuentos como "El hombre", "Paso del Norte", "Es que somos muy pobres", "Nos han dado la tierra": "Se echó de vuelta al río y la corriente se soltó zangoloteándolo como un reguilete, y hasta por poco se ahoga. Dio muchos manotazos y por fin no pudo pasar y salió allá abajo, echando buches de agua hasta desentriparse" (Rulfo, 2014: 36) y "Yo sólo vengo a decirle que allí en un charco del río está un difunto. Y usted me alega que desde cuándo y cómo es y de qué modo es ese difunto. Y ora que yo se lo digo, salgo encubridor. Pos ora sí" (38).

Por otro lado, a la prosa oral la definimos como un modo literario narrativo donde la voz del narrador va integrando giros, vocabulario e inflexiones propias de la lengua local. Este recurso está más presente en los cuentos de El llano en llamas (1953) de Rulfo que en los relatos de Garibay correspondientes a los años 1945-1955 ("La nueva amante", "El despertar", "Los adioses", "El rubio Elkan", "El deseo", "El General Frijoles", "Alemán tomando cerveza", "Sintaxis elemental", "Lo que pasa", "Náufragos", "La noche terrible", "Mazamitla", "Legítima defensa", "instantáneas de la muerte y de la espera", "Matías y el ángel", "El coronel"). Este rasgo corresponde con aquello que Ángel Rama identificara como un lenguaje literario transculturado, ese que combina de manera orgánica dentro del discurso los registros del habla de los personajes y la lengua del narrador literario. Rama se refiere en Transculturación narrativa en América Latina precisamente a autores que, como Juan Rulfo y Ricardo Garibay, pueden ser considerados al mismo tiempo herederos e innovadores de las tradiciones literarias que les preceden. Más particularmente, para estos autores que buscaban renovar los modos narrativos del realismo regionalista, "el léxico, la prosodia y la morfosintaxis de la lengua regional, apareció como el campo predilecto para prolongar los conceptos de originalidad y representatividad" (Rama, 2004: 42) y lograr la integración del autor-narrador dentro de la comunidad lingüística donde se mueven sus personajes. Tal operación trasculturadora abona excelentes frutos en el campo de la ambientación narrativa que transporta al lector de los textos a las realidades referidas en los relatos. Algunos de los recursos de la prosa oral que encontramos en Rulfo coinciden con algunas de las marcas de oralidad señaladas por Ong, como las reiteraciones que se emplean para representar frases idiomáticas o para recalcar una idea anterior: "No hay nada. A no ser de unos cuantos huizaches trespeleques y una que otra manchita de zacate con las hojas enroscadas; a no ser eso, no hay nada. [...] Pero no hay agua. Ni siquiera para hacer un buche hay agua. [...] y ni aun así es positivo que nazca nada; ni maíz ni nada nacerá" (9-10, el subrayado es nuestro).

Dentro de la prosa oral, igualmente destacan las referencias a la vida del campo. Por ejemplo, Pichón, el narrador de "El llano en llamas", usa varias comparaciones con animales oriundos de la región para describir los acontecimientos durante su época de rebelde: "Sentíamos 
las balas pajueleándonos los talones, como si hubiéramos caído sobre un enjambre de chapulines. [...] habíamos subido hasta el otro lado, a gatas, como tejones espantados por la lumbre. [...] Era como si se nos hubiera acabado el habla a todos o como si la lengua se nos hubiera hecho bola como la de los pericos..." (72).

Otro aspecto importante de la prosa oral en Rulfo, y que coincide también con las características descritas por Ong, es la preferencia por conjunciones de estilo aditivo en lugar de subordinadas. En "Acuérdate", cuento narrado en primera persona, el narrador une sus ideas a través de la conjunción " $y$ ":

...tenía dos hijas muy juguetonas: una prieta y chaparrita que por mal nombre le decían la Arremangada, y la otra que era retealta y que tenía los ojos zarcos y que hasta se decía que ni era suya y que por más señas estaba enferma del hipo. Acuérdate del relajo que armaba cuando estábamos en misa y que a la mera hora de la Elevación soltaba su ataque de hipo, que parecía como si se estuviera riendo y llorando a la vez, hasta que la sacaban afuera y le daban tantita agua con azúcar y entonces se calmaba. (125)

Aparte de estos elementos señalados por Ong, Rulfo utiliza otras estrategias adicionales para representar la inmediatez referencial y el carácter denotativo asociados al lenguaje oral. El uso de adjetivos demostrativos enfatiza la naturaleza denotativa de la narración: “...los ventarrones que soplan por este tiempo sobre el Llano. Así que se veía muy bonito ver caminar el fuego en los potreros; ver hecho una pura brasa casi todo el llamo en la quemazón aquella [...] aquel humo oloroso a carrizo y miel..." (77, el subrayado es nuestro). $\mathrm{O}$ en Garibay: "Esto sucedía veinte años después de aquella noche, cuando Juan Paredes, poco antes de morir, le gritó a Maximiano Llamas..." (Garibay, 2001: 100, el subrayado es nuestro).

En alguna ocasión, puede el narrador rulfiano incluso interpelar al lector como si se tratara de una audiencia contigua subrayando la impresión de un narrador que habla a un interlocutor: "Era un hombrón así de grande, que hasta daba coraje estar junto a él y sopesar su fuerza, aunque fuera con la mirada [...] Ojalá que ninguno de los presentes se ofenda por si es de allá, pero yo me sostengo en mi juicio" (Rulfo, 2014: 146).

Otro rasgo que juega un papel fundamental dentro de una prosa oral es el empleo de dilatados diálogos entre los personajes. Sin embargo, se observa una diferencia en el tratamiento dado a este recurso dentro de los cuentos de Rulfo y de los de Garibay. En el caso de El llano en llamas, los personajes se presentan como pares ("Paso del Norte" y "Anacleto Morones"), mientras que en los relatos de Garibay, como "El General Frijoles" y "La noche terrible", el interlocutor del campesino es un hombre letrado y esta jerarquía se transporta lingüísticamente al texto.

Un aspecto adicional relacionado con la representación de la oralidad dentro de la prosa es el que identificamos en cierto encadenamiento sostenido a lo largo de varias páginas de un torrente de frases que traducen el flujo del habla. Se trastocan la sintaxis y la puntuación propias del discurso escrito para convertir el texto en una reproducción verosímil del devenir oral. En otras palabras, nos encontramos ante un ritmo ininterrumpido que se sucede sin mayores respiros:

Dijo que cuando la hoy occisa le prometió quererlo y que él la querría, sintió como si la miraba desde ámbitos oscuros; que lo miró acercándose y él vio su rostro maltratado y cubierto de finos 
bellos, entre los que resaltaban a la comisura izquierda de los labios, dos más largos, no rubios, sino negros y gruesos, y sintió que no podría amarla nunca porque ella era desgraciada; pero ella lo miraba quemándolo y siguió diciendo cosas que lo llenaron de inquietud. (Garibay, 2001: 114)

Acuérdate que a su madre le decían la Berenjena porque siempre andaba metida en líos y de cada lío salía con un muchacho. Se dice que tuvo su dinerito, pero se lo acabó en los entierros, pues todos los hijos se le morían de recién nacidos y siempre les mandaba cantar alabanzas, llevándolos al panteón entre músicas y coros de monaguillos que cantaban "hosannas" y "glorias" y la canción esa de "ahí te mando, Señor, otro angelito". De eso se quedó pobre porque le resultaba caro cada funeral, por eso de las canelas que les daba a los invitados del velorio. Sólo le vivieron dos, el Urbano y la Natalia, que ya nacieron pobres y a los que ella no vio crecer, porque se murió en el último parto que tuvo, ya de grande, pegada a los cincuenta años. (Rulfo, 2014: 126)

Antes de continuar hasta nuestro siguiente punto, quisiéramos resaltar otro tipo de flujo narrativo menos vinculado a la representación del habla y más asociado a las técnicas expresivas conocidas como el fluir de la conciencia o el monólogo interior. Este recurso que surgió como una experimentación formal dentro de la prosa novelística occidental en la primera mitad del siglo XX, cobra un sentido particular dentro del contexto de la prosa intensamente oral de Juan Rulfo y Ricardo Garibay. ¿Qué queremos decir con esta afirmación? Nos referimos aquí a una escritura que fluye ininterrumpidamente, de manera semejante a la prosa oral que comentáramos hace un momento. Sin embargo, estamos aquí ante un recurso intensificado, llevado al extremo en el fluir desatado que se extiende por varias páginas sin mayor interrupción. No hay párrafos que organicen pausas textuales, ni mayores interrupciones. En su lugar, nos encontramos ante un sintagma que se distiende por varias líneas, remitiéndonos de nueva cuenta a la noción de un flujo verbal incontenible. Dos cuentos en particular, uno de Rulfo y otro de Garibay, son representativos de este flujo de conciencia. Ninguno de ellos presenta divisiones de párrafos y, en el caso de "Macario", la estructura sintáctica remeda la agilidad de las frases habladas.

De cualquier modo, yo estoy más a gusto en mi cuarto que si anduviera en la calle, llamando la atención de los amantes de aporrear gente. Aquí nadie me hace nada. Mi madrina no me regaña porque me vea comiéndome las flores de su obelisco, o sus arrayanes, o sus granadas. Ella sabe lo entrado en ganas de comer que estoy siempre. Ella sabe que no se me acaba el hambre. Que no me ajusta ninguna comida para llenar mis tripas aunque ande a cada rato pellizcando aquí y allá cosas de comer. Ella sabe que me como el garbanzo remojado que le doy a los puercos gordos y el maíz seco que le doy a los puercos flacos. Así que ella ya sabe con cuánta hambre ando desde que me amanece hasta que me anochece. Y mientras encuentre de comer aquí en esta casa, aquí me estaré. Porque yo creo que el día en que deje de comer me voy a morir, y entonces me iré con toda seguridad derechito al Infierno. (Rulfo, 2014: 66)

Era algo dulce rendirse allí tras la ventana de su biblioteca, mirando clarear la tarde a estas palomas que le traían desde tan lejos las vacaciones de su infancia, la vida, luego, luego la-vida no había sido tan dañosa, no siempre tuvo que temer al despertar del día siguiente ni las gentes lo recibieron con la maledicencia, hubo un tiempo en que vivió saludable y ajeno a todo mal, apañado en el amor de los otros, seguro de salvación; uno se siente subir mirando las palomas, lejos de este calor, estos aires enrarecidos, médicos echados sobre la cama, frascos y potingues, subir sudores ardientes entre el helado viento de la tarde... jadeando... (Garibay, 2001: 57) 
Este flujo de conciencia en "Macario" y "El despertar" tienen en común que son secuencias que demandan imaginación de parte del autor quien no funciona como mero transcriptor de un habla o un modo de expresión, sino como explorador de una subjetividad que le es ajena, como es el caso del pensamiento del joven retrasado en "Macario" o el flashback del personaje agonizante de "El despertar". En ambos ejemplos estamos ante flujos especulativos en el sentido en que el escritor supone aquello que pasa por la cabeza de un niño con retardo mental o por la mente de un moribundo en los minutos finales de su existencia.

El rol jugado por la imaginación del autor se verá respaldado en el plano formal de la escritura por un trabajo cuidadoso con respecto a la estructuración del relato. Estos dos elementos, creación y organización de las historias, apuntan hacia una dirección distinta a la que señalaba el trabajo de la oralidad dentro de la prosa. Si bien la prosa coloquial u oral nos podría hacer pensar en una primera instancia en cierta modalidad del relator oral, al estilo señalado por Walter Benjamin en su conocido ensayo "The Storyteller", una segunda aproximación nos lleva a reconocer las experimentaciones formales que tanto Rulfo como Garibay emplean en la estructuración de sus cuentos. Si bien es cierto que la cuentística de Rulfo y Garibay que gira alrededor de la vida en el campo mexicano responde a un fenómeno de oralidad cultural, que se encarga de representar discursivamente a las comarcas rurales mediante procedimientos estéticos y narrativos, también reconocemos otro tipo de innovaciones formales que remodelan los paradigmas narrativos del regionalismo tradicional (Pacheco). En este sentido, escritores al estilo de Rulfo y Garibay fueron distinguidos por la crítica literaria con apelativos como el de superregionalistas o neorregionalistas para destacar sus incursiones en una narrativa decididamente moderna y precursora de posteriores narrativas transculturadoras.

\section{Formas híbridas}

Juan Rulfo y el Ricardo Garibay de los cuentos con ambientación rural, se pueden considerar junto a Agustín Yáñez y José Revueltas como los renovadores de la tradición del realismo regionalista en el México de mediosiglo. Una vez agotado el ciclo de la novela de la Revolución, estos autores retomaron de manera original el tópico del campo, de una geografīa y unos personajes atados a una vida trágica y azarosa. En Rulfo y Garibay, el cuento de tema rural se convirtió en la ocasión idónea para ciertas exploraciones formales que luego se verterían en sus muy logradas novelas, Pedro Páramo (1955) y La casa que arde de noche (1971), respectivamente.

Dentro del catálogo de tales exploraciones formales, enfatizaremos el tratamiento de la estructura narrativa que contrasta con aquellas de los relatos lineales del realismo regionalista o criollista. Los cuentos de El llano en llamas comparten con estos últimos una temática asociada con la experiencia del campesino mexicano, pero la expresión formal con la que se aborda este universo es claramente novedosa, como lo reconoceremos en la técnica del adelgazamiento del narrador y en el empleo del diálogo como soporte narrativo.

En "Paso del Norte" y "El día del derrumbe", el recurso del desdibujamiento de un narrador encargado de conducir el relato alcanza su mejor expresión, puesto que en estos textos, 
Rulfo deja la historia en boca de los personajes quienes se encargan de tramar la anécdota a través de sus diálogos. Poco o ningún espacio se consigna para una voz narrativa convencional o para comentarios autoriales como los que se reconocían en obras del realismo regionalista. Rulfo mismo consideraba este adelgazamiento de la voz autorial como un procedimiento esencial, aunque laborioso, para el cuentista moderno: "Una de las cosas más difíciles que me ha costado hacer, precisamente, es la eliminación del autor, eliminarme a mí mismo", explicaba el escritor jalisciense en su discurso "El desafío de la creación" (Rulfo, 1980: 16).

Cuando en "El Paso del Norte" y "El día del derrumbe" el relato se desenvuelve gracias a la conversación sostenida entre los personajes, estas intervenciones dejan de figurar como meros fragmentos prosódicos del habla campesina que se distinguen de la prosa de un narrador extradiegético. Se produce entonces una impresión de unidad estilística donde se "[recuperan] las formas inconexas y dispersivas de la narración oral pero ajustadas a una unificación que ya procede del impacto modernizador" (Rama, 2004: 47). Rulfo emplea la técnica de la "eliminación del autor", al tiempo que la temática y el ambiente local son representados a través la anécdota dialogal entre dos personajes campesinos.

En este manejo narrativo, Rulfo dejaba entrever su descreimiento acerca de una jerarquía que colocaba al autor por sobre sus personajes y sus lectores. Al prescindir, parcial o totalmente, del narrador, él jugaba a una suerte de "muerte del autor", evitando caer en la tentación de cierto narrador realista que relata y enjuicia a la vez. Aunque "El día del derrumbe" omita en apariencia a un narrador extradiegético, no deja de percibirse en este cuento una posición autorial frente al asunto recogido en sus páginas. El diálogo que orquesta el relato es de un tono claramente satírico, dejando entrever una figura espectral del autor, de un Rulfo crítico ante la demagogia inoperante de los dirigentes y gobernantes de las zonas rurales en el México postrevolucionario.

En contraste con los relatos del realismo regionalista, las historias de Rulfo no siguen la fórmula representada por el famoso diagrama de Freitag. Cuentos como "Luvina" o "Macario" minimizan la acción, privilegiando en su lugar la descripción y el tono narrativo. En "Luvina", por ejemplo, predomina la imagen del ambiente lúgubre y desolador que el narrador intradiegético (ese que cuenta su experiencia como habitante de aquel pueblo) logra transmitir. En cuanto a "Macario", el relato es logrado mediante un monólogo interior que nos pone en contacto con las vivencias de un personaje mentalmente retrasado. Tanto en "Luvina" como en "Macario", la prosa no acusa la economía expresiva tradicionalmente reservada al género del relato breve. Sin embargo, el receptor se mantiene atento al relato y cautivado por ese flujo verbal abundante, que en principio pudiera pensarse que actuaría en detrimento de la atención lectora. Rulfo, sin incluir un clímax o un desenlace como lo exigiera la fórmula de Freitag, alcanza una gran intensidad en sus narrativas.

Otro aspecto innovador en "Luvina" es la incorporación de elementos fantásticos dentro del relato. Luvina es descrito como un pueblo lleno de personajes fantasmales y en donde el tiempo está estancado "como si se viviera siempre en la eternidad" (Rulfo, 2014: 107). Asimismo, la combinación entre elementos realistas y fantásticos será central dentro de Pedro Páramo, considerada la obra maestra de Rulfo. Las experimentaciones formales en cuanto al estilo y la estructura narrativa en los cuentos de El llano en llamas tendrían repercusión en la 
producción literaria latinoamericana en las siguientes décadas, tal y como lo señala Rama —entre otros críticos-.

Por su parte, el abanico de exploraciones formales en Garibay no alcanzó la diversidad y maestría que Rulfo lograra en su volumen de relatos, pero hay sin duda aciertos formales que vale la pena subrayar para referirnos a la modernidad de esta cuentística temprana de Garibay. A pesar de que algunos de estos relatos transparentan cierto experimentalismo propio de los talleres de creación literaria que frecuentara Garibay en los años que nos ocupan, otros nos dejan ver un narrador que empieza a dominar de manera propia algunas de las técnicas de la fragmentación de la historia, de la perspectiva narrativa múltiple, de la conversión de la arquitectura textual en motivo relevante temática y estilísticamente hablando.

A este respecto vamos a centrar nuestros comentarios en dos de los cuentos que a nuestro juicio condensan los logros de Garibay en materia del entramado formal de sus historias: "Mazamitla" (1953) e "Instantáneas de la muerte y de la espera" (1955). "Mazamitla" es, sin duda alguna, el texto más logrado de esta época, y aunque originalmente se le publicara como novela breve en la colección Los Presentes, pasó luego a incorporarse a sus volúmenes de cuentos supervisados por el propio Garibay, como es el caso de La tierra prometida (1998). De hecho, los dos cuentos a los que haremos referencia se incluyen en esta compilación que reúne relatos de distintas épocas dentro de la obra del escritor hidalguense.

"Mazamitla" e "Instantáneas de la muerte y de la espera" se encuentran divididos en breves apartados encabezados por números romanos. Estos apartados no se organizan siguiendo una secuencia lineal, sino que representan saltos retrospectivos y prospectivos de la historia. Ambos, además, se inician con la escena bastante efectista de una muerte que constituirá un motivo central en la trama. El tema de la muerte violenta dentro del ámbito de las narraciones en torno a un escenario rural no es rasgo innovador, pero sí lo es la manera en la que el narrador nos presenta las imágenes que introducen el relato. En el caso de "Mazamitla", la escena participa sin duda de la estética y el ritmo cinematográfico: "Levantó la cabeza hacia las nubes veloces, se destocó, paseó una mano sobre los largos cabellos, espeso sudor hervía en su frente, abrió el compás de sus piernas, miró abajo, y volvió a buscar la luna" (94). Estas descripciones breves nos hacen pensar en las acotaciones de un libreto más que en los modos de las descripciones propias de la prosa literaria. La agilidad con la que se suceden los gestos y movimientos del personaje (Juan Paredes) provocan en el lector la impresión de una secuencia cinematográfica, y nos imaginamos incluso a esta escena dentro de la paleta blanco y negra que asociamos con las películas mexicanas de la época. Hay en la gestualidad del personaje una compostura que relacionamos con los protagonistas de la gran pantalla.

Similarmente, el inicio de "Instantáneas de la muerte y de la espera" nos remite a unos movimientos de cámara, a una perspectiva "en picada", que abre con una vista aérea de Metztitlán hasta enfocar en detalle al cuerpo tendido sobre el suelo. La yuxtaposición así creada entre una descripción a cargo de una prosa oral y la perspectiva asociada a una visión camarográfica anuncia desde el comienzo una hibridez entre elementos asociados con la cultura rural, por un lado, y con la modernidad, por el otro: el imaginario asociado al campo mezclado 
con la tecnología de la escritura moderna. Una escritura que no solo combina diferentes planos espaciales dentro del texto, sino que disloca igualmente el plano temporal de la narración.

El manejo de la estructura narrativa, el relato que avanza y retrocede en el tiempo, alternativamente, convierte al texto en una especie de rompecabezas que debe rearmar el lector, prestando atención a las claves ofrecidas. En el caso de "Mazamitla", a esta fracturación del tiempo que se corresponde con cada apartado, se le combina con una frase final, una variante de la misma idea que actúa simultáneamente como pista temporal y como la repetición (recurso mnemotécnico) propia de los fabuladores orales: "Esto sucedía la noche en que mataron a Juan Paredes" (94); "Esto sucedía una semana después del fusilamiento" (95); "Esto pasaba al día siguiente, y aún dos y tres días después de la noche del cementerio" (96); "Esto sucedía ocho años después, entre dos soldados de aquel antiguo regimiento..." (97).

Es importante considerar las experimentaciones narrativas empleadas por Rulfo y Garibay para entender cómo estos escritores logran, a partir de su propio estilo, mezclar elementos de la oralidad con técnicas literarias contemporáneas, pero también para reconocer cómo estas formas híbridas de narración evidencian una brecha entre el espacio rural y el urbano. Como explica Antonio Cornejo Polar, en narrativas heterogéneas como las que nos ocupan, "las instancias de producción, realización textual y consumo pertenecen a un universo sociocultural y el referente a otro distinto" (Quijano Velasco, 2012: 37). Asimismo, a pesar de que los relatos discutidos en este estudio se concentran en una temática asociada al ámbito rural mexicano, Rulfo y Garibay tienen como receptor implícito a un lector urbano y cosmopolita literariamente hablando, aquel que está familiarizado con ciertas estructuras y técnicas literarias innovadoras. Más aún, esta factura moderna de los cuentos de Rulfo y de Garibay hizo posible la recepción internacional de una obra que, además de sus exploraciones estructurales y estéticas, narraba historias de significación universal. Los dramas de estos personajes atrapados en un mundo que no les ofrece mayor espacio para la esperanza o para el gozo nos remiten a paradigmas universales del drama humano. No sorprende entonces que los cuentos reunidos en El llano en llamas hayan sido traducidos a una veintena de idiomas.

\section{Bibliografía}

BENJAMIN, Walter (2008): El narrador. Santiago de Chile, Ediciones Metales Pesados. CORNEJO POLAR, Antonio (1994): Escribir en el aire. Lima, Editorial Horizonte. GARIBAY, Ricardo (2001): Obras reunidas 1. México, Océano.

ONG, Walter (2012): Orality and Literacy. New York, Routledge. DOI: https://doi.org/10.4324/9780203103258

PACHECO, Carlos (1996): "Transculturación, ruralidad y oralidad en la narrativa de Alfredo Armas Alfonso". Asedios a la heterogeneidad cultural. Coords. José Antonio Mazzoti y U. Juan Zevallos Aguilar. Filadelfia, Asociación Internacional de Peruanistas: 419-430. 
QUIJANO VELASCO, Mónica (2012): Transculturación, heterogeneidad e hibridación: Tres conceptos de crítica literaria y cultural en América Latina. México, Universidad Nacional Autónoma Mexicana.

RAMA, Ángel (2004): Transculturación narrativa en América Latina. México, Siglo XXI.

RULFO, Juan: "El desafío de la creación". Revista de la Universidad de México 2-3 (1980): 1517.

--- (2014): El llano en llamas. México, RM.

(C) Anadeli Bencomo

(C) Andrés Vázquez

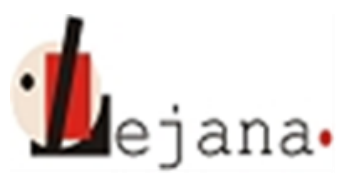

http://ojs.elte.hu/index.php/lejana

Universidad Eötvös Loránd, Departamento de Español, 1088 Budapest, Múzeum krt. 4/C 